\title{
The effect of yoyo bitters on the dissolution of metformin tablets
}

\begin{abstract}
Background: Yoyo bitters is an oral poly herbal liquid preparation popularly marketed and used in Nigeria. Its use is rapidly increasing among patients with chronic diseases such as diabetes and hypertension. This is because it has been claimed to regulate blood pressure, control body weight, and facilitate digestion among others. Metformin is an oral anti diabetic agent. Both the incidences of Diabetes and use of Yoyo bitters are increasing hence setting the stage for possible co-administration of these two agents. This also increases the potential for Herb-drug interaction. The aim of the study is to investigate the effect of Yoyo bitters on the dissolution of metformin tablets.
\end{abstract}

Methods: Physicochemical tests (Weight uniformity, Crushing strength, Friability and Assay) were carried out on two different brands of metformin tablets and physical properties of the Yoyo bitters were also determined. The in-vitro dissolution of metformin tablets with and without Yoyo bitters in dissolution media was then carried out at $\mathrm{pH}$ 1.2, 4.5 and 6.8 using United States Pharmacopoeia (USP) apparatus 1 (basket) at 100rpm with $900 \mathrm{ml}$ of the dissolution medium (sink condition) maintained at a steady temperature of $37 \pm 0.5^{\circ} \mathrm{C}$. Two different brands metformin $500 \mathrm{mg}$ immediate release tablets were used and the analysis was done using UV-Spectrophotometer at a wavelength of $232 \mathrm{~nm}$.

Results: The results obtained show that at $\mathrm{pH} 1.2$, the percentage amount of metformin released decreased significantly in the presence of Yoyo bitters for both brands $(\mathrm{p}=0.002$ and $\mathrm{p}=0.013$ respectively). At $\mathrm{pH} 4.5$ there was no significant difference in metformin released for the Diabetmin ${ }^{\circledR}(\mathrm{p}=0.196)$ and a significant difference was observed with Sandoz ${ }^{\circledR}$ $(\mathrm{p}=0.045)$. At $\mathrm{pH} 6.8$, a significant decrease in percentage metformin released in the presence of Yoyo bitters was observed for both brands ( $\mathrm{p}=0.011$ and $\mathrm{p}=0.044$ respectively).

Conclusion: Yoyo bitters decreased the dissolution of metformin tablets at $\mathrm{pH}$ 1.2, 4.5 and 6.8. Due to therapeutic failure, toxicity etc caused by decreased dissolution, concomitant use of metformin and Yoyo bitters should be discouraged.

Keywords: yoyo bitters, metformin, dissolution, diabetes
Volume 5 Issue I - 2017

\author{
Igbokwe N, Madu SJ, Muazu J \\ Department of Pharmaceutics and Pharmaceutical Microbiology, \\ University of Maiduguri, Nigeria
}

Correspondence: Jamilu Muazu, Department of Pharmaceutics and Pharmaceutical Microbiology, University of Maiduguri, Nigeria,Tel 8037439543, Email jmuazu@unimaid.edu.ng

Received: October 31, 2016 | Published: June 12, 2017

\section{Introduction}

The World Health Organization (WHO) defined herbal medicine as: 'any part of a plant in which one or more of its parts can be used for therapeutic purposes or as precursors for the synthesis of useful drugs. Herbal medicines include herbs, herbal materials, herbal preparations and finished herbal products that contain parts of plants or other plant materials as active ingredients. ${ }^{1}$ Prior to the advent of modern medicines, use of herbal remedies was the only available treatment known to mankind hence the use of herbal remedies for several decades by people from diverse cultures. Based on a report of WHO global survey, the use of herbal medicine throughout the world has exceeded the use of conventional therapies by two to three times. While $90 \%$ of the population in Ethiopia use herbal remedies for their primary healthcare, surveys carried out in developed countries like Germany and Canada show that at least $70 \%$ of their population have tried complementary or alternative medicine at least once. ${ }^{2}$ About $25 \%$ of drugs prescribed worldwide are derived from plants. ${ }^{3}$

Herbal bitters are blends of herbs, spices, roots, seeds and bark used as a tonic to aid in digestion, particularly of heavy fatty meals. Medicinal herbal bitters on the other hand contain blended ingredients in a water or alcohol base used for the treatment of illnesses. Bitters contain complex carbohydrates, secondary metabolites, vitamins and minerals that have antioxidant, antiviral and other pharmacological properties. They are used to aid digestion and metabolism, relieve occasional heartburn, calm upset stomach and nausea, increase absorption of fat soluble vitamins, help maintain healthy blood sugar levels, ease constipation and regulate bowel movements, help mop up free radicals and stimulate immune function among others. ${ }^{4}$ Herbal bitters are used all over the world, some notable examples of bitters available today include: Alomo Bitters (Ghana), Amaro Montenegro (Italy), AmerPicon (France), Aperol(Italy), Araucano (Valparaíso, Chile), Averna(Italy), Balsam (Eastern Europe), Becherovka (Czech Republic), Beerenburg (Netherlands), Blutwurz(Bavaria), Calisaya (USA), Campari (Italy), FernetBranca (Italy), Fernet Stock (Czech Republic), Gammel Dansk(Denmark)Jägermeister (Germany), Jepson's (United States), Killepitsch (Düsseldorf, Germany), Kuemmerling (Germany), Pelinkovac (Balkans), Quinquina (France - originally from South America), Ramazzotti (Italy), Ratzeputz (Germany), Riga Black Balsam(Latvia), Schierker Feuerstein (Germany), Schwartz hog (Germany), St. Vitus (Germany), Sirop de Picon (France), Suze (France), Underberg (Germany), Unicum (Hungary), WódkaŻołądkowaGorzka (Poland), Wurzelpeter (Germany).

Yoyo Bitters, a typical example of a commercially marketed herbal bitter, is an oral preparation popularly used in Nigeria which is contained various parts of plants such as Aloe vera, Cinnamum aromaticum, Citrus aurantifolia, Acinos arvensis, and Chenopodium 
murale. $^{5}$ Its use is common among patients with chronic diseases like hypertension and diabetes. ${ }^{6}$

Herb-drug interaction refers to the possibility of an herbal drug altering the bioavailability or clinical effectiveness of a conventional drug when given concurrently. ${ }^{7}$ Since herbal medicines contain more than one pharmacologically active ingredient and are commonly used with many prescribed drugs, there are potential herb-drug interactions. The concurrent use of herbal and drug combinations may raise the potential of drug- herb interactions as observed in some studies. Ginkgo biloba was reported to cause bleeding with warfarin and acetylsalicylic acid. ${ }^{8}$ Hypericumperforatum (St. John's wort) has been reported to decrease plasma concentrations of cyclosporine, tacrolimus, oral contraceptives, simvastatin, nifedipine, and verapamil. ${ }^{9}$ Both the incidences of chronic diseases (hypertension and diabetes) and the use of herbal bitters are increasing, thus, setting the stage for potential co-administration of antihypertensive/ anti diabetics and herbal remedies. The aim of the study is therefore, to investigate the effect of Yoyo bitters on the dissolution profiles of metformin tablets.

\section{Materials and method}

Metformin tablets (Diabetmin ${ }^{\circledR}$ and Sandoz ${ }^{\circledR}$ ) were purchased from pharmacy unit of University of Maiduguri Teaching Hospital, Yoyo bitters was purchased from a registered retail pharmacy, Sodium hydroxide (BDH chemicals, Poole, England). Hydrochloric acid (BDH chemicals, Poole, England). Potassium dihydrogen orthophosphate, Acetic acid, Sodium acetate monohydrate, Weighing balance (Sartorious, Germany), PH meter (Jenway, Japan), Hardness Tester (Erweka Germany), Friability Tester (Erweka, Germany), Dissolution Tester (Erweka DT-700, Germany), 6405 UV/Vis. Spectrophotometer (Barlowood scientific, UK).

\section{Uniformity of weight test of metformin tablets}

The USP method was adopted, twenty tablets were randomly selected from each brand and weighed individually. The mean weight of the tablets was then calculated and the standard deviation was determined.

\section{Crushing strength for metformin tablets}

The Erweka hardness tester (TBH 100, Germany) was used in measuring the crushing strength of the tablets. Six (6) tablets were randomly selected from each brand; each of these tablets was in turn placed between the anvil and the spindle of the hardness tester and subjected to increasing pressure by turning the knurled knob in a clockwise direction at constant rate until the tablet was crushed. The value of the pressure applied at this point gives a measure of the hardness. The mean and standard deviation of the six determinations was then taken for each sample.

\section{Friability test for metformin tablets}

The USP method was adopted, ten tablets were randomly picked from each brand and weighed accurately. They were then placed inside the drum of friabilator (Erweka, Germany) and operated for $4 \mathrm{~min}$ at a speed of $25 \mathrm{rpm}$. Thereafter, the intact tablets were removed from the drum, dusted and weighed. The percentage loss in weight was calculated and recorded as friability value for that sample.

\section{Assay of metformin tablets}

The USP method was adopted with slight modification, five tablets were weighed and powdered. A quantity containing $0.1 \mathrm{~g}$ of metformin was shaken with $70 \mathrm{ml}$ of water for $15 \mathrm{~min}$, it was diluted to $100 \mathrm{ml}$ with distilled water and filtered. The first $20 \mathrm{ml}$ was discarded, $10 \mathrm{ml}$ of the filtrate was diluted with $100 \mathrm{ml}$ water and $10 \mathrm{ml}$ of the resulting solution was further diluted to $100 \mathrm{ml}$ with water to obtain $10 \mu \mathrm{g} / \mathrm{ml}$. The absorbance was measured at a wavelength of $232 \mathrm{~nm}$ using UV spectrophotometer (Barlowond scientific, UK).

\section{Physicochemical characterization of yoyo bitters}

The colour of Yoyo bitters was determined by visual inspection of the liquid preparation and recorded. The taste and $\mathrm{pH}$ of the herbal product were also determined.

\section{Dissolution time test}

The USP method was adopted, the dissolution medium was prepared as described earlier, ${ }^{7} 300 \mathrm{ml}$ of Yoyo bitters was measured in a $1000 \mathrm{ml}$ measuring cylinder, and $0.1 \mathrm{~N} \mathrm{HCl}$ was added to make $1 \mathrm{~L}$ of the dissolution medium. The media without yoyo bitters was $0.1 \mathrm{~N} \mathrm{HCl}$, for the dissolution test $900 \mathrm{ml}$ was used while the remaining volume was used to maintain sink conditions. The same procedure was repeated for acetate buffer and phosphate buffer. The $0.1 \mathrm{~N} \mathrm{HCl}$ and acetate buffer were prepared according to USP while the phosphate buffer was prepared according to the British Pharmacopoeia (BP) method. In vitro dissolution test was carried out using tablet dissolution test USP apparatus 1 (basket). The dissolution test was carried out in three media without Yoyo bitters: $0.1 \mathrm{~N} \mathrm{HCl}$ at $\mathrm{pH} 1.2$, acetate buffer at $\mathrm{pH} 4.5$ and phosphate buffer at $\mathrm{pH} 6.8$; and three media containing Yoyo bitters. The temperature of the dissolution medium was maintained at $37 \pm 0.5^{\circ} \mathrm{C}$ at a speed of $100 \mathrm{rpm}$. A tablet was placed in each vessel and the equipment operated for $60 \mathrm{~min}$. Sample aliquots of $10 \mathrm{ml}$ were taken at $5,15,30,45$ and $60 \mathrm{~min}$ and replaced with $10 \mathrm{ml}$ of fresh dissolution medium to maintain sink conditions. The experiment was done in triplicate. Each of the withdrawn samples was diluted to $100 \mathrm{ml} ; 10 \mathrm{ml}$ of the resulting solution was taken and further diluted to $100 \mathrm{ml}$ then filtered through a $0.45 \mu \mathrm{m}$ membrane filter discarding the first $20 \mathrm{ml}$ filtrate. The filtrate was then analyzed at a wavelength at $232 \mathrm{~nm} .{ }^{10}$ using UV-VIS spectrophotometer. The experiment was carried for the two brands of metformin tablets in media with and without yoyo bitters at $\mathrm{pH} 1.2,4.5$ and 6.8.

\section{Data analysis}

SPSS version 16.0 was used in the analysis of the data using paired $t$-test at a level of significance of $p<0.05$.

\section{Results}

Table 1 shows the physicochemical parameters of the metformin tablets. Table 2 represents the physical properties of Yoyo bitters. Dissolution of a drug in solid dosage form into an aqueous medium is critical for its absorption, which in turn has an impact on its bioavailability and therapeutic efficacy. Variables such as weight uniformity, hardness, friability and percentage purity also play important roles in the efficient release of the drug for systemic absorption. ${ }^{11}$ These parameters were therefore carefully analysed before carrying out the dissolution studies. The results obtained from weight uniformity and friability tests (Table 1) conformed to the specifications in the United States Pharmacopoeia. ${ }^{12}$

The $\mathrm{pH}$ of the Yoyo bitters was 3.4 (Table 2) which showed that it is acidic in nature. This could be due to some of its constituents such as Cinnamon aromaticum which contains Cinnamic acid, Citrus aurantifolia containing Citric acid and Ascorbic acid and Acinosarvensis which contains Linoleic acid. ${ }^{13}$ A research by Olubunmi et al. ${ }^{7}$ recorded the $\mathrm{pH}$ of the Yoyo bitters used as 5.8 . 
This variation in $\mathrm{pH}$ could be due to batch to batch differences mostly caused by poor adherence to strict quality control measures. A study. ${ }^{14}$ on chemical 0 and alkaloids has been known to be responsible for the bitter taste observed in many foods and herbs. This can probably account for the bitterness of Yoyo bitters.

Table I Physicochemical Parameters of Metformin Tablets

\begin{tabular}{lll}
\hline Parameter & $\begin{array}{l}\text { Observation } \\
\text { Diabetmin } ®\end{array}$ & Metformin Sandoz 8 \\
\hline Shape & Round & Round \\
Colour & White & white \\
Embossment & HD & M 500 \\
Uniformity of weight $(\mathrm{g})$ & $0.56 \pm 0.06$ & $0.52 \pm 0.05$ \\
Crushing strength $(\mathrm{KgF})$ & $\mathrm{II} .75 \pm \mathrm{I} .52$ & $\mathrm{I} 3.4 \mathrm{I} \pm 2.6 \mathrm{I}$ \\
Friability (\%) & 0.02 & 0.02 \\
Assay (\% purity) & $97.47 \pm 6.33$ & $95.32 \pm 3.1 \mathrm{I}$ \\
\hline
\end{tabular}

Table 2 Results of Physical Properties of Oral Liquid Yoyo bitters

\begin{tabular}{ll}
\hline Parameter & Observation \\
\hline Color & Brownish black \\
Taste & Bitter \\
$\mathrm{pH}$ & 3.4 \\
\hline
\end{tabular}

Figures 1-3, illustrates the dissolution profiles of metformin alone and with Yoyo bitters at $\mathrm{pH} 1.2,4.5$ and 6.8 respectively. From the graphs it can be seen clearly that there is evidenced reduction in the dissolution profile of metformin due to the presence of Yoyo bitters at all $\mathrm{pH}$ levels.

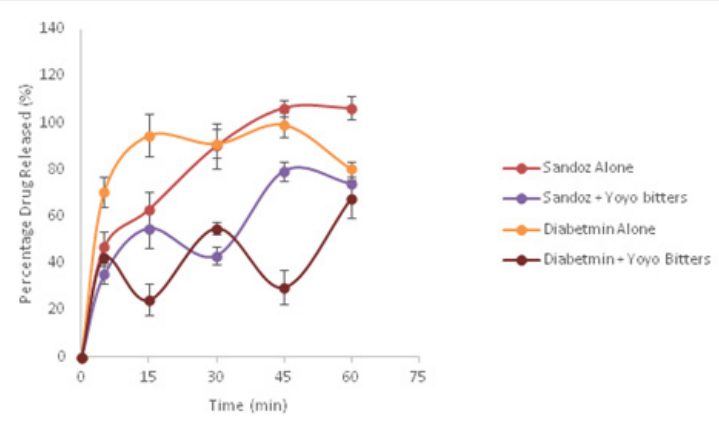

Figure I Dissolution profiles of metformin (Diabetmin $\AA$ and Sandoz $\AA$ ) with and without Yoyo bitters in media at $\mathrm{pH}$ 1.2. $(\mathrm{p}<0.05)$.

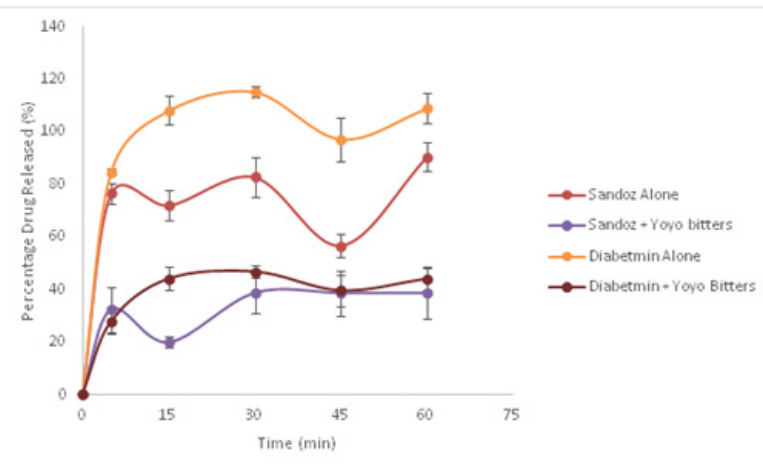

Figure 2 Dissolution profiles of metformin (Diabetmin $₫$ and Sandoz $®$ ) with and without Yoyo bitters in media at $\mathrm{pH} 4.5$.

The results obtained from the experiment showed that for both brands of metformin tablets, at $\mathrm{pH} 1.2$, which mimics the acidic nature of the stomach, the percentage release of metformin without Yoyo bitters conformed to the BP. ${ }^{15}$ standard which states that, $70 \%$ drug should be released within $30 \mathrm{~min}$. This means that the two brands of metformin (Diabetmin ${ }^{\circledR}$ and Sandoz $\left.{ }^{\circledR}\right)$ passed the dissolution test at this $\mathrm{pH}$ but in the presence of Yoyo bitters, a decrease in the percentage release of metformin was observed for both Brands. This implies that the tablets did not pass the dissolution test in the presence of Yoyo bitters as not up to $70 \%$ of the drug was released in both cases.

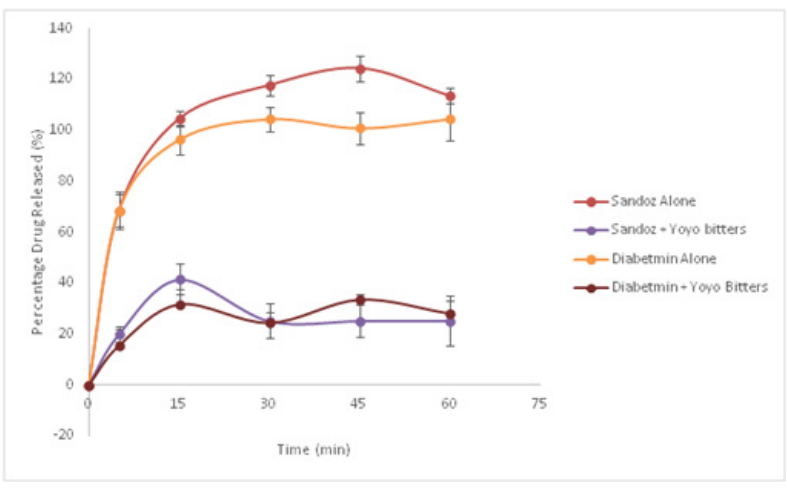

Figure 3 Dissolution profiles of metformin (Diabetmin $®$ and Sandoz $®$ ) with and without Yoyo bitters in media at $\mathrm{pH}$ 6.8. $(\mathrm{p}<0.05)$.

Figures I-3 show the dissolution profiles of metformin tablets alone and in the presence of Yoyo bitters at pH I.2, 4.5 and 6.8.

The paired t-test for metformin in media with and without Yoyo bitters for Diabetmin ${ }^{\circledR}$ and Sandoz ${ }^{\circledR}$ showed a significant difference ( $p=0.002$ and $p=0.013$ respectively) in percentage release of metformin. At $\mathrm{pH} 4.5$, the percentage metformin alone released for both brands of metformin used in the experiment conformed to the specification in the monograph of metformin as stated in the BP (2009). In the presence of Yoyo bitters, the percentage release of metformin decreased but the decrease with Diabetmin ${ }^{\circledR}$ is not significant $(p=0.196)$ whereas that of Sandoz ${ }^{\circledR}$ is statistically significant $(\mathrm{p}=0.045)$. This $\mathrm{pH}$ mimics the transit between the stomach and small intestine.

At $\mathrm{pH} 6.8$ which is the $\mathrm{pH}$ of the small intestine, both brands of metformin alone also conformed to the monograph of metformin USP. With Yoyo bitters, the percentage metformin released was lower than that seen in metformin without Yoyo bitters; hence the tablets did not pass the dissolution test in the presence of Yoyo bitters as not up to $70 \%$ of the drug was released within the stipulated time frame. The difference in percentage release is statistically significant as observed with Diabetmin ${ }^{\circledR}(p=0.011)$ as well as with $\operatorname{Sandoz}{ }^{\circledR}(p=0.044)$.

Yoyo bitters probably impaired the solubility of metformin either by chelation or by forming insoluble complexes, thereby hampering the release of metformin. This could possibly account for the change in the dissolution profiles in its presence. Analysis of Yoyo Bitters as reported by Olubunmi et al. ${ }^{7}$ eluted a number of substances that could not be identified. These constituents could have interacted with the process of dissolution at all the stages. Again, Yoyo bitter is a mixture of about five herbs, Aloe vera inclusive. A report by Chavez et al. ${ }^{16}$ stated that herbs like Aloe vera and other anthraquinone-containing herbs could inhibit absorption of conventional drugs as a result of chelation or formation of insoluble complexes with the drugs.

The absorption of metformin takes place primarily in the small intestine, ${ }^{17}$ therefore the dissolution observed at $\mathrm{pH} 6.8$ is critical to the absorption or bioavailability of the drug as this $\mathrm{pH}$ mimics the small intestine. This is of huge clinical relevance as the decrease in dissolution of metformin tablets could lead to a decrease in absorption of the active ingredient and in turn bioavailability of the drug. Decreased bioavailability can result to decreased concentration at site of action hence treatment failure resulting to poor glycaemic 
control, diabetic complications such as uncontrolled hypertension, posing a threat to some organs of the body like the eyes, heart, brain and kidneys thereby compromising positive clinical outcomes in patients taking such medications. Concurrent use of Yoyo bitters and metformin tablets can increase the potential for herb-drug interaction, which may have significant clinical consequences.

\section{Conclusion}

The two brands of metformin tablets passed the quality control parameters. Yoyo bitters decreased the dissolution of metformin tablets at $\mathrm{pH} 1.2,4.5$ and 6.8 which may affect efficacy, safety etc and therefore, concomitant use of the metformin and Yoyo bitters should be discouraged.

\section{Acknowledgments}

None.

\section{Conflicts of interest}

The authors declare no conflicts of interest related to this article.

\section{Funding}

None.

\section{References}

1. Mahomoodally MF. Traditional Medicines in Africa: An Appraisal often Potent African Medicinal Plants. Evidence-Based Complementary and Alternative Medicine. 2013;2013:1-14.

2. Gurib-Fakim A. Medicinal plants:traditions of yesterday and drugs of tomorrow. Mol Aspects Med. 2006;27(1):1-93.

3. Sanjoy KP and Yogeshwer S. Herbal Medicine: Current trends. Asian Pacific Journal of Cancer Prevention. 2003;4(4):281-288.

4. Alabi MA, Sunday RM, Olowokere T, et al. Effect of bitters on the body weight, lipid profile, catalase and lipid peroxidation in experimental animals. J Med Sci. 2013;13(1):62-66.

5. Kumdi BV, Kolawole JA, Apeh E. The effect of Yoyo bitters on the pharmacokinetics of single oral dose Paracetamol tablet in human volunteers. Int J Biol Chem Sci. 2011;5(2):717-723.
6. Ogbera AO, Dada O, Adeyeye F, et al. Complementary and alternative medicine use in diabetes mellitus. West Afr J Med. 2010;29(3):158-162.

7. Olubunmi AA, Olubukola OO, Moshood OA. Effect of Yoyo Bitters on the Dissolution of Lisinopril Tablets. J Dissolution technologies. 2015:6-10.

8. Hu Z, Yang X, Ho PCL, et al. Herb- Drug Interactions. Drugs. 2005;65(9):1239-1282.

9. Borrelli F, Izzo AA. Herb-Drug Interactions with St John's Wort (Hypericum perforatum):an Update on Clinical Observation. AAPS J. 2009;11(4):710-727.

10. Umapathi P, Ayyappan J, Quine SD. Quantitative determination of metformin hydrochloride in tablet formulation containing croscarmellose sodium as disintegrgant by HPLC and UV spectrophotometry. Tropical Journal of Pharmaceutical Research. 2012;11(1):107-116.

11. Akinleye MO, Jolaoso AA, Coker HAB. Comparative Dissolution Profiles of Representative Quinolones in Different Media. Niger $Q J$ Hosp Med. 2011;21(1):1-8.

12. USP. The U. S. Pharmacopeial Convention. USA:United States Pharmacopoeia; 2007.

13. Stojanovic G, Golubovic T, Kitic D, et al. Acinos species:Chemical composition, antimicrobial and antioxidative activity. J Med Plants Res. 2009;3(13):1240-1247.

14. Onyeaghala AA, Omotosho IO, Shivashankara AR. Cytotoxicity of Various Fractions of Compounds Extracted from Yoyo Bitters on Human Cervical Cancer Cells. European Journal of Medicinal Plants. 2015;7(2):46-58.

15. British Pharmacopoeia. Her Majesty's stationary office. London, USA: British Pharmacopoeia; 2009.

16. Chavez ML, MacKinnon KJ, Swanson LS. Herbal-Drug Interactions. INET Continuing Education (InetCE). 2005;9(10):1-30.

17. Marathe PH, Yandong W, Jean N, et al. Effect of altered gastric emptying and gastrointestinal motility on metformin absorption. $\mathrm{Br} \mathrm{J} \mathrm{Clin}$ Pharmacol. 2000;50(4):325-332. 